\title{
APPLICATION OF CITICOLINE IN SUPPORTING THERAPY OF SELECTED DISEASES
}

\author{
JOANNA PIOTROWSKA ${ }^{1 *}$, AGATA KRYCZYK-POPRAWA ${ }^{1}$, BOŻENA MUSZYŃSKA $^{2}$, \\ ANDRZEJ PILC ${ }^{3}$, and WŁODZIMIERZ OPOKA ${ }^{4}$ \\ ${ }^{1}$ Department of Inorganic and Analytical Chemistry, Jagiellonian University Medical College, \\ Cracow, Poland \\ ${ }^{2}$ Department of Pharmaceutical Botany, Jagiellonian University Medical College, Cracow, Poland \\ ${ }^{3}$ Institute of Pharmacology, Polish Academy of Sciences, Cracow, Poland \\ ${ }^{4}$ Department of Inorganic and Analytical Chemistry, Jagiellonian University Medical College, \\ Cracow, Poland
}

\begin{abstract}
Citicoline (exogenous CDP-choline) is a nootropic (procognitive) compound and a psychostimulant. This substance exhibits a strong neuroprotective effect: it participates in the synthesis of phosphatidylcholine, a vital component of cell membranes, thus supporting the processes of synthesis and regeneration of neuron membranes. It stimulates synaptogenesis via its capacity to inhibit the process of demyelination process and promotes myelin regeneration. In addition, it prevents apoptosis of the neurons. The application of citicoline improves the health status of persons diagnosed with a stroke, brain trauma, as well as in patients with Alzheimer's disease. Citicoline administered to patients diagnosed with Parkinson's disease enables reducing the therapeutic dose of levodopa and, as a consequence, decrease the level of adverse events. What is more, scientific research has shown that citicoline applied in this clinical entity has a positive impact on the motor function of the patient. Citicoline improves memory and concentration in the elderly, resulting in improved cognitive functions in demented conditions. The neuroprotective properties of citicoline suggest its application in the treatment of patients diagnosed with glaucoma, a neurodegenerative disorder. Improvement of the vision parameters was observed independent of the route of administration (intramuscularly, intravenously, orally, or in the form of eye drops) of drugs containing citicoline. Citicoline administration in addiction treatment (cocaine, methamphetamine) has produced positive effects. Application of this substance in alcohol withdrawal syndrome treatment improves concentration and orientation in space-time. Citicoline has low toxicity, which has been confirmed via animal testing and clinical studies.
\end{abstract}

Keywords: glaucoma, Parkinson's disease, Alzheimer's disease, addiction treatment, citicoline

CDP-choline (cytidine-5'-diphosphocholine) is a mononucleotide (Fig. 1) found normally in all cells of the human organism.

The structure of CDP-choline includes choline, which is also a component of acetylcholine. The role of choline as a component of acetylcholine,

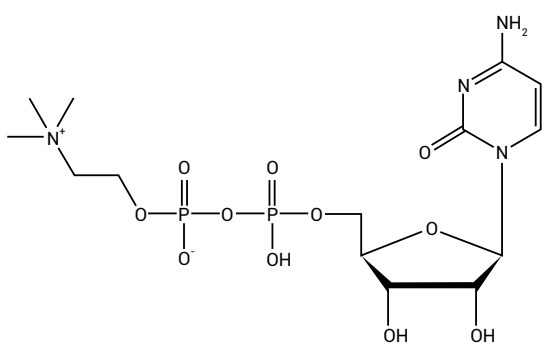

Figure 1. Structural formula of cytidine-5'-diphosphocholine. a neurotransmitter, was described in the works of $\mathrm{H}$. Dale and O. Loewi $(1,2)$, for which they received the Nobel Prize in 1936. Choline (2-hydroxyethyl(trimethyl) ammonium cation) was identified as a vital functional component in 1988. The daily demand for choline in the human organism increases with age, and it also depends on the sex and physiological status: it is at its peak for men and breastfeeding women where it amounts to $550 \mathrm{mg} /$ day (3). Choline is the precursor of numerous metabolic pathways in the human organism, participating, among others, in the synthesis of acetylcholine and phospholipids (lecithin and sphingomyelin). Its oxidation products are betaine, also known as N,N,N-trimethylglycine (Fig. 2): chaperone and methyl

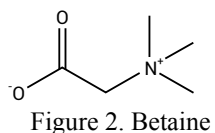


group donor in the synthesis pathway running via methionine and cysteine to peptides and proteins.

It has been demonstrated that the low supply of choline in the diet leads to hepatic insufficiencies, exhibited by increased activity of ALT and AST aminotransferases in the serum of the examined patients and steatosis of this organ. In addition, serum increase of creatine kinase CPK was found, which is a muscle damage marker (4). It has been demonstrated that choline contributes to the normal development of the nervous system of the fetus, and its deficiency disturbs absorption of the folic acid. What is more, choline improves blood flow in the placenta, protecting pregnant women against preeclampsia $(5,6)$.

Researchers demonstrated in 1954 that its derivative, CDP-choline, is a precursor in the metabolic pathway of lecithin biosynthesis (phosphatidylcholine) (Fig. 3) (7).

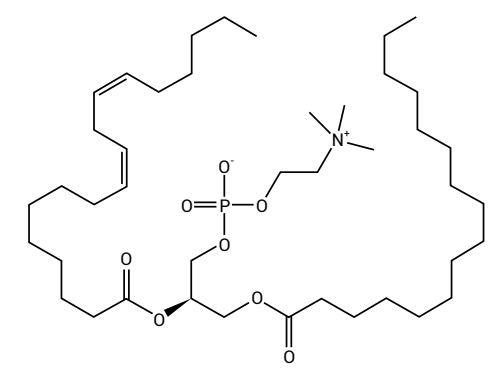

Figure 3. Lecithin structural formula.

Two years later, the substance was isolated from Saccharomyces cerevisiae yeast extract and its physicochemical properties were described (8). Citicoline is the international, non-proprietary name of CDP-choline; this name is used with regards to the pharmaceutical substance which is a component of drugs and diet supplements, contrary to CDP-choline, which is an endogenous substance. According to the anatomical, therapeutic and chemical classification of drugs issued by the World Health Organization (WHO) citicoline is a nootropic and psychostimulatory substance, listed under code no. N06BX06 (9).

The use of citicoline was commenced in Japan for Parkinson's disease patients at the beginning of the 1970s in the form of an injection (10). When oral preparations were developed, they started to be applied in diet supplements. An active form of the substance is sodium salt or inner salt (C14H25N4NaO11P2). The European Food Safety Authority (EFSA) issued in 2013 a positive scientific opinion on the citicoline safety of use. The entity justified its position by the fact that citicoline and its molecules: cytidine, choline, and phosphate group are naturally found in the human organism participating in documented metabolic processes, and are also supplied with food (11). Citicoline exhibits low toxicity and does not present systemic cholinergic effects (12). This has been proven by the conducted testing: LD50 in mouse amounts to $4.6 \mathrm{~g} /$ $\mathrm{kg}$, in rats after intravenous administration: $4.15 \mathrm{~g} /$ $\mathrm{kg}$, and in oral administration $8 \mathrm{~g} / \mathrm{kg}$ (13). For humans, the mean daily therapeutic citicoline dose is $500-2000 \mathrm{mg}$, which is approx. 7-29 $\mathrm{mg} / \mathrm{kg}$ of body weight for a person with a mean body weight of $70 \mathrm{~kg}$.

Citicoline is soluble in water and it is characterized by high bioavailability, as over $90 \%$ of the oral dose penetrates to the general circulation. The pharmacokinetics has been assessed after administration of a single oral dose of $300 \mathrm{mg}$ of the compound marked with ${ }^{14} \mathrm{C}$ carbon isotope (14). Absorption was basically complete, and less than $1 \%$ of the dose was determined in the stool for daily uptake for 5 days. Two peaks in the radioactivity time profile in the serum: first after 1 hour, and second, higher, after 24 since administration. Elimination of metabolism products in the form of $\mathrm{CO}_{2}$ occurs with exhaled air and with urine (14). The biological half-life of citicoline in the phase of its elimination in the human organism is $\mathbf{5 6 - 7 1}$ hours. Its distribution and activity in the human organism after its oral, intramuscular, intravenous administration, as well as administered to the conjunctival swab, is equal as in intravenous administration. Citicoline hydrolysis should lead to equimolar amounts of choline and cytidine, however, in a rat study (15) it was shown that after oral administration of citicoline, the increase in the molar plasma cytidine concentration was greater than choline concentration. The human study showed that the increase in plasma choline concentration after citicoline ingestion was delayed and proceeded in two phases. It is possible that citicoline is absorbed intact and its hydrolysis takes place in the liver (16, 17). After oral administration, citicoline is hydrolyzed in the intestinal epithelium, resulting in the formation of choline and cytidine. It has been demonstrated that neurons utilize these metabolites after approx. 30 minutes from administration (18). The formed molecules easily penetrate the blood-brain barrier, are rephosphorylated and CDP-choline is resynthesized by the phosphocholine cytidiltransferase enzyme (19). CDP-choline, as well as products of its hydrolysis, participate in the biosynthesis of acetylcholine, nucleic acids, and methionine (20). The following chart (Fig. 4) presents the metabolic transformations of citicoline in the human organism.

As a result of the reactions occurring in the human organism, cytidine is transformed into uridine, followed by its phosphorylation to uridine 


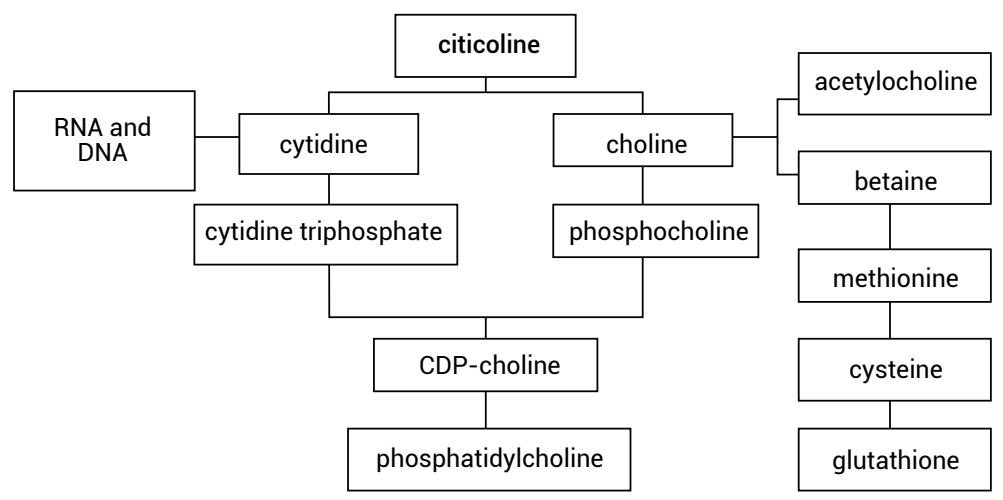

Figure 4. Diagram
of metabolism of citicoline
in the human body.

triphosphate it is transformed into cytidine triphosphate (CTP) (Fig. 5) (21).

CDP-choline is an endogenous intermediate product of phosphatidylcholine (lecithin), to which it bears a structural resemblance. In terms of amounts, phosphatidylcholine constitutes half of the brain phospholipids. The major phospholipids that form cell membranes are phosphatidylcholine (Fig. 3), phosphatidylethanolamine, and phosphatidylserine (Fig. 6) (22).

$\mathrm{X}$ :

$-\left(\mathrm{CH}_{2}\right)-\mathrm{NH}_{2}$ phosphatidylethanolamine $-\mathrm{CH}_{2}-\mathrm{CH}\left(\mathrm{NH}_{2}\right)-\mathrm{COOH}$ phosphatidylserine

$\mathrm{R}_{1}, \mathrm{R}_{2}$ : carbon chain of a fatty acid molecule

Experiment, in which rats were administered citicoline for the period of 42 and 90 days demonstrated that the brain concentration of phosphatidylcholine increased by $25 \%$, phosphatidylethanolamine by $17 \%$, whereas phosphatidylserine by $42 \%$ (23). In nervous system disorders, the CDP-choline mechanism of action consists in stimulating the synthesis of phospholipids in the membranes of nerve cells (24).

The pharmacological action of citicoline in the central nervous system has pleiotropic nature. It has been demonstrated that citicoline protects nerve cells from degeneration via i.a. influence of synaptogenesis (25). The experiment conducted on primary neuronal cultures from the somatosensory cortex demonstrated that the application of citicoline increased the length of the axons, number of branching points, and the surface occupied by neurons (26). As a result of citicoline administration to experimental animals, increased synthesis of phospholipids in the brain was determined $(27,28)$. Evidence showed that citicoline uptake in spinal cord ischemia increased the tissue expression of the Bcl-2 antiapoptotic protein (28). In animal models of multiple sclerosis, citicoline was found to inhibit the demyelination process and stimulation of myelin reconstruction, which is used to create the coats of nerve pathway axons in the spinal cord and in the brain white matter (29). It has been further proven that citicoline largely protects neurons against the toxic influence of glutamate, which is the main transmitter in stimulating synapses of the brain $(30,31)$. Following permanent middle cerebral artery occlusion (pMCAO), which resulted in increased glutamate concentration in the brain, treatment with citicoline ( $2 \mathrm{~g} / \mathrm{kg}$ b.w.) inhibited this growth. Furthermore, citicoline $(100 \mu \mathrm{M})$ produced intensified glutamate uptake in the cultures of astrocytes, via increasing expression of EAAT2 proteins transporting glutamate (32). These authors suggest that citicoline reduces the intracellular accumulation of glutamate after ischemia via reduced efflux and concomitant increased uptake of glutamate by astrocytes, thus reducing the excitotoxicity $(32,33)$.

In addition, citicoline increases the expression of sirtuin-1 (SIRT-1) in the brain - an enzyme classified among histone deacetylases (basic proteins forming a part of chromatin). SIRT-1 activation process in the cells combats aging and development of diseases that result from old age (30).

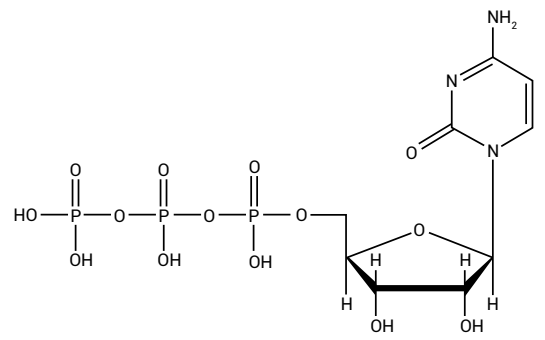

Figure 5. Structural formula of cytidine triphosphate.<smiles>[X]OP(=O)(O)OCC(COC([R])=O)OC([R])=O</smiles>

Figure 6. Structural formula of phosphatidylethanolamine and phosphatidylserine. 


\section{Examples of diseases for which citicoline is used Ischemic stroke}

According to the World Health Organization, stroke is the second most common cause of death in people over 60 and fifth in the age range of 15-59. Exogenous citicoline inhibits apoptotic mechanisms of neurons associated with brain ischemia, prevents accumulation of free fatty acids, including arachidonic acid and protects against activation of A2 phospholipase, an enzyme responsible for phospholipid degradation to fatty acids and lysophospholipids. (31). Furthermore, citicoline accelerates regeneration of nerve cells and strengthens the neuroplasticity mechanisms, as well as facilitates rehabilitation and regaining consciousness in the treatment of patients with ischemic dysfunctions of the central nervous system (12). Evidence also showed that the compound inhibits the formation of free radicals (32). In addition, research showed the efficacy of citicoline in the treatment of cognitive and depressive dysfunctions in prolonged brain ischemia of patients aged 35-80 with arterial hypertension and/or atherosclerotic disease. The drug was administered at a dose of $1000 \mathrm{mg}$ per day for 30 days. Improvement of cognitive functions, memory, and visual-spatial coordination, as well as reduced intensity of depression symptoms, were observed (33).

\section{Trauma brain injury}

Trauma Brain Injury (TBI) constitutes another indication for citicoline administration, as it is a precursor in the synthesis of membrane phospholipids, which are subject to destruction after brain trauma. In a clinical study consisting of intravenous administration of citicoline at a dose of $1000 \mathrm{mg}$ / day to patients, improvement of cognitive and motor functions was observed in the group of patients taking the drug in contrast to the control group (18). In turn, in a study conducted on a group of patients with trauma brain injury, no improvement could be discerned for the functional and cognitive status of patients, who were administered citicoline orally or intragastrically at a dose of $2000 \mathrm{mg}$ /day for 90 days (34). No influence of citicoline administration on the awareness level of TBI patients, assessed using the Glasgow Coma Scale (GCS) was demonstrated. It was determined that citicoline may protect against negative changes, such as inflammatory damage and vessel calcification, which are consequences of head trauma (35). Also, Meshkini et al. demonstrated the lack of benefits of citicoline application for trauma brain injury. However, these researchers confirmed improved cognitive functions in TBI patients (36).

\section{Parkinson's disease}

Citicoline is used in Parkinson's disease, in the course of which dopaminergic neurons of the nigrostriatal pathway are damaged, and which connects the substantia nigra with the striatum. Dopaminergic drugs are applied in the disease's pharmacotherapy, including dopamine precursors, dopamine receptor agonists, levodopa and dopamine metabolism inhibitors, and anticholinergics. Levodopa is the most efficient drug in Parkinson's disease, however, its administration is burdened with central and peripheral adverse reactions. The central symptoms include increased motor activity, insomnia, dyskinesia, choreic involuntary movements concerning the head and limbs, mood disorders, nausea, vomiting, hormonal disorders (increased growth hormone level, reduced prolactin level). Peripheral symptoms include arrhythmias, orthostatic hypotension, increased glomerular filtration rate, gastrointestinal tract disorders, and excessive sweating. As a result of the conducted study, it has been determined that the concomitant application of levodopa with citicoline enables reduction of levodopa dose, also decreasing the adverse reactions to the drug (18). The efficacy of CDP-choline stems from its capacity to increase dopamine concentration in the striatum and substantia nigra of the human midbrain (37). In a study conducted in a group of patients administered with citicoline intramuscularly at a dose of $500 \mathrm{mg} /$ day reduction of bradykinesia and joint stiffness in patients was observed (38). In another study, experts assessed the efficiency of citicoline in the treatment of behavioral and emotional disorders and the therapy of cognitive deficits caused by chronic brain diseases in elderly people. As a result of the conducted research, a conclusion was drawn stating that citicoline has a positive impact on memory, behavior, and the general medical condition of a patient (39).

\section{Alzheimer's disease}

Alzheimer's disease has a neurodegenerative character and consists of an ongoing loss of mental and cognitive functions, concerning primarily people aged above 65 . The basic role in the pathogenesis of this disease is the loss of damage of cholinergic, glutamatergic, 5-HT-ergic, adrenergic neurons, GABA-ergic neurons within the hippocampus, cortex, and subcortical structures region - particular near the basal nucleus of Meynert. The degenerative changes are the outcome of the extracellular accumulation of glycoprotein senile plaques or amyloid plaques formed from $\beta$-amyloid. As a consequence, memory, concentration, and perception dysfunctions 
occur. The patient loses contact with their environment, is delusional, irritable, and aggressive (40, 41). In pharmacotherapy, drugs improving the cognitive functions are used, which inhibit the clinical course and facilitate the functioning of the patient. Symptomatic treatment consists of the use of cholinesterase inhibitors and NMDA receptor antagonists for patients $(42,43)$. Other pharmacotherapy methods include administration of acetylcholine precursors (phosphatidylcholine, lecithin), use of nootropic drugs, and drugs improving circulation and brain metabolism. The efficacy rate of citicoline was tested for people diagnosed with Alzheimer's disease. Based on the conducted experiments, scientists drew a conclusion that improvement of cognitive parameters and increased blood flow in the brain vessels was observed in patients who were administered citicoline. What is more, the improved bioelectric activity of the brain was recorded, and attention was paid to the absence of adverse effects of the drug use (24, 46). It was further demonstrated that the concomitant administration of citicoline and acetylcholinesterase inhibitors (rivastigmine, donepezil) has a synergistic impact on increased acetylcholine concentration in the inter-synaptic spaces and improves the results of tests assessing cognitive functions (MMSE - Mini-Mental State Examination), functional fitness (ADL - Activities of Daily Living, IADL Instrumental Activities of Daily Living) and mood (GDS - Geriatric Depression Scale) of patients diagnosed with Alzheimer's disease, for whom combined therapy was used for 3 and 9 months (47).

\section{Glaucoma}

Considering that in glaucoma, as well as in neurodegenerative disorders, atrophy of membrane structures of neurons occurs, citicoline has been applied also for this disease entity. In 2013, 44 million people had glaucoma, and it is estimated that in 2020 this group will grow to about 53 million people (48). According to the data of the World Health Organization, glaucoma is the second cause of irreversible visual loss. The essence of the disease is the optic nerve injury, characterized by ongoing changes within the optic nerve disc and visual field defects. Research revealed that citicoline fulfills a protective function towards the nerve cells in the eye retina and improves the field of vision parameters in glaucoma patients, who were administered with the substance in the form of intramuscular injections, orally or in the form of eye drops $(49,50)$. Polish scientists have brought a significant contribution, showing the neuromodulatory and neuroprotective effect of citicoline in the eye retina (51). Citicoline administered orally in glaucoma patients induces protection of the ganglion cell complex of the retina and improves parameters of the so-called visual evoked potentials (52). Visual Evoked Potentials (VEP) are electric potentials recorded in the occipital region formed during the signal transfer from the retina to the brain by visual means, appearing as a response to a visual stimulus. Their measurement is an objective method of examining a patient's vision. In animal models, research has documented the effect of citicoline consisting in increasing dopamine concentration in the eye retina of rabbit (53) and increased expression of the Bcl-2 protein as well as influence on the regeneration of axons of the rat retina coil (54). Also a combination of citicoline and homotaurine synergistically decreases proapoptotic effects associated with glutamate- and high glucose-treated retinal cultures (55).

\section{Treatment of addictions and psychiatric disorders}

Via the use of MR spectroscopy, Yoon et al. demonstrated an increase of $\mathrm{N}$-acetylaspartate concentration in the prefrontal areas of the brain, which is a marker of neuron viability, at the simultaneous negative results of the test for the presence of methamphetamine in the urine of addicted patients, who were administered with citicoline at the dose of $2000 \mathrm{mg} /$ day (56). A different experiment showed that such dosing resulted in alleviation of depression symptoms in individuals addicted to methamphetamine (57).

A study conducted in groups of people taking cocaine provided evidence that citicoline at the dosage of $500 \mathrm{mg} /$ day improves control, and at the same time reduces the need for taking the drug, whereas at the four-fold higher dose it further improves memory $(58,59)$. Other research carried out in a group of cocaine-addicted did not determine its addiction reducing effect $(60,61)$.

People with alcohol withdrawal syndrome (AWS), who were administered $1000 \mathrm{mg}$ citicoline per day for 60 days, exhibited improved concentration and time-and-space orientation, however, no reduced alcohol consumption could be determined for the examined (62).

Influence of citicoline on food intake was also a subject of study - its administration at the dose of $2000 \mathrm{mg}$ /day for 6 weeks was considerably reducing appetite which was correlated with the functional changes in the selected brain areas responsible for appetite (amygdala, insula, lateral orbitofrontal cortex). However, body weight reduction was not determined for the patients (63). 
An experiment was conducted, which was used to demonstrate the benefits of combined therapy of citalopram and citicoline in patients with major depression. Introduction of citicoline at a dose of $200 \mathrm{mg} /$ day for 6 weeks enabled obtaining improved condition of the examined, for whom depression symptoms were assessed via the Hamilton Depression Rating Scale (HDRS) at the beginning of the study and on 2nd, 4th, and 6th week of therapy (64).

A risperidone and citicoline $(2500 \mathrm{mg} /$ day for 8 weeks) combined therapy efficiently reduces the adverse symptoms in patients with schizophrenia. Patients' condition was assessed via the Positive and Negative Syndrome Scale (PANSS), Extrapyramidal Rating Scale (ESRS), and the Hamilton Depression Rating Scale (HDRS) (65).

\section{Safety of citicoline use}

In 1983 a study was carried out in a group of 2817 patients aged 60-80 diagnosed with neurological disorders, associated primarily with cardiovascular failure. It has been demonstrated that citicoline administered orally at a dose of $600 \mathrm{mg} /$ day for 15 to 60 had a considerable impact on reducing adverse effects (dizziness and headache, memory and speech disorders, insomnia) and was well tolerated by $95 \%$ of the examined. The observed adverse events mostly concerned gastrointestinal disorders (stomachache, diarrhea, nausea) - they were reported by $3.6 \%$ of the examined. Adverse effects of the cardiovascular system (low blood pressure, bradycardia) were observed in less than $1 \%$ of patients (62). Fioravanti et al. established that citicoline application in elderly patients with neurological dysfunctions was associated with a lower incidence of somatic adverse events than in the case of placebo (63). The safety of citicoline use was further confirmed by its administration in acute ischemic stroke and trauma brain injury at a dosage of $4000 \mathrm{mg} /$ day $(34,64,65)$.

Good tolerance and absence of adverse side effects of the applied citicoline doses were determined in the research concerning its possible use in methamphetamine and cocaine addiction therapies $(57,61)$.

\section{Summary}

Citicoline (cytidine-5'-diphosphocholine) is vital for the normal synthesis and reconstruction of neural membranes and functioning of the acetylcholine nucleic acid and protein synthesis pathways. It should be emphasized, that it is absorbed by the organism after oral, and intramuscular administration as well as administration to the conjunctival swab, and its bioavailability is equal as in intravenous administration.
Citicoline has been registered in Poland as a drug (Proaxon) to be used in neurological and cognitive disorder conditions, resulting from a cerebrovascular event, e.g. stroke or brain trauma. The recommended dosing is $1000-2000 \mathrm{mg} /$ day depending on the clinical status of the patient. Diet supplements containing citicoline are also available on the market.

It has also been registered for use in cognitive dysfunctions, depression and glaucoma in the European Union, USA, and Japan. Therapeutic benefits of citicoline application in schizophrenia and its influence on reducing appetite have been demonstrated. The substance is characterized by a high safety profile, absence of systemic cholinergic effects, and proven therapeutic efficacy rate. In combined therapy, it enables reducing levodopa dose and reducing the adverse central and peripheral nervous system symptoms. In addition, its application is beneficial for the treatment of drug (methamphetamine, cocaine) and alcohol-addicted individuals.

\section{Conflict of interest}

The authors declare no conflicts of interest.

\section{REFERENCES}

1. Dale H.: J. Pharm. Exp. Ther. 6, 147 (1914).

2. Loewi O.: Pflügers Archiv. 189, 239 (1921).

3. Food and Nutrition Board, Institute of Medicine. Dietary Reference Intakes: Thiamin, Riboflavin, Niacin, Vitamin B-6, Vitamin B012, Pantothenic Acid, Biotin, and Choline. National Academies Press, Washington (DC) 1998.

4. Fischer L.M., da Costa K., Kwock L.: Am. J. Clin. Nutr. 85, 1275 (2007).

5. Jiang X., Bar H.Y., Yan J., Jones S., Brannon P.M., et al.: FASEB J. 27, 1245 (2013).

6. Dávalos A., Alvarez-Sabín J., Castillo J., DíezTejedo E., Ferro J., et al.: Lancet 380, 349 (2012).

7. Kennedy E.P.: J. Biol. Chem. 209, 525 (1954).

8. Berger L., Gimenez W.T.: Science 124, 81 (1956).

9. https://www.whocc.no/atc_ddd_index/?code= N06BX06\&showdescription=no; (accessed on 27.04.2021).

10. Tsubaki T., Kase M., Ando K., Manaka N., Sato Y.: Nihon Rinsho 32, 3435 (1974).

11. Scientific Opinion on the safety of "citicoline" as a Novel Food ingredient. EFSA J. 11 (2013) 1-22 https://www.efsa.europa.eu/en/efsajournal/ pub/3421 (accessed on 28.04.2021).

12. Secades J.J., Lorenzo J.L.: Methods Find. Exp. Clin. Pharmacol. 28, 1 (2006). 
13. Schauss A.G., Somfai-Relle S., Financsek I., Glavits R., Parent S.C., et al.: Int. J. Toxicol. 28, 479 (2009).

14. Dinsdale J.R., Griffiths G.K., Rowlands C., Castelló J., Ortiz J.A. et al.: Arzneimittelforschung 33, 1066 (1983).

15. Lopez-Coviella I., Agut J., Savci V., Ortiz J.A., Wurtman R.J.: J. Neurochem. 65, 889 (1995).

16. Sarkar A.K., Ghosh D., Haldar D., Sarkar P., Gupta B.. et al.: J. Pharm. Biomed. Anal. 71, 144 (2012).

17. Grieb P.: CNS Drugs 28, 185 (2014).

18. Adibhatla R.M., Hatcher J.F.: J. Neurosci. Res. 70, 133 (2002).

19. Kent C., Carman G.M.: Trends Biochem. Sci. 24, 146 (1999).

20. Weiss G.B.: Life Sci. 56, 637 (1995).

21. Wurtman R.J., Regan M., Ulus I., Yu L.: Biochem. Pharmacol. 60, 989 (2000).

22. Sastry P.S.: Prog. Lipid Res. 24, 69 (1985).

23. López-Coviella I., Agut J., Savci V., Ortiz J.A., Wurtman R.J.: J. Neurochem. 65, 889 (2002).

24. Franco-Maside A., Caamaño J., Gómez M.J., Cacabelos R.: Methods Find. Exp. Clin. Pharmacol. 16, 597 (1994).

25. Wurtman R.J., Cansev M., Sakamoto T., Ulus I.H.: Annu. Rev. Nutr. 29, 59 (2009).

26. Rema V., Bali K.K., Ramachandra R., Chugh M., Darokhan Z., et al: Neuroscience 155, 556 (2008).

27. Agut J., Lopez G., Coviella I., Ortiz J.A., Wurtman R.J.: Ann. N. Y. Acad. Sci. 695, 318 (1993).

28. Turkkan A., Alkan T., Goren B., Kocaeli H., Akar E., Korfali E.: Acta Neurochir. (Wien) 152, 1033 (2010).

29. Skripuletz T., Manzel A., Gropengießer K., Schäfer N., Gudi V., et al.: Brain 138, 398 (2015).

30. Hurtado O., Moro M.A., Cárdenas A., Sánchez V., Fernández-Tomé P., et al.: Neurobiol. Dis. 18, 336 (2005).

31. Radad K., Gille G., Xiaojing J., Durany N., Rausch W-D.: Int. J. Neurosci. 117, 985 (2007).

32. Hurtado O., Moro M.A., Cárdenas A., Sánchez V., Fernández-Tomé P., et al.: Neurobiol. Dis. 29, 123 (2008).

33. Dennis E.A., Cao J., Hsu Y.H., Magrioti V., Kokotos G.: Chem. Rev. 111, 6130 (2011).

34. Clarck W.M.: Expert Opin. Pharmacother. 10, 839 (2009).

35. Mashin V.V., Belova L.A., Dudikov E.M., Bergelson T.M., Lankov V.A., Zakuraeva K.A.: Zh. Nevrol. Psikhiatr. Im. S.S. Korsakova 117, 44 (2017).
36. Zafonte R.D., Bagiella E., Ansel B.M., Novack T.A., Friedewald W.T., et al.: JAMA 308, 1993 (2012).

37. Shokouhi G., Ghorbani Haghjoo A., Sattarnezhad N., Asghari M., Sattarnezhad A., et al.: Ulus. Travma Acil Cerrahi Derg. 20, 410 (2014).

38. Meshkini A., Meshkini M., Sadeghi-Bazargani H.: J. Inj. Violence Res. 9, 41 (2017).

39. Rejdak R., Rękasa M.: Podstawy neuroprotekcji w jaskrze i chorobach zwyrodnieniowych siatkówki. Via Medica, Gdańsk 2017 (in Polish).

40. Conant R., Schauss A.G.: Altern. Med. Rev. 9, 17 (2004).

41. Qureshi I., Endres J.R.: Nat. Med. J. 2, 11 (2010).

42. Apostolova L.G.: Continuum (Minneap., Minn.) 22, 419 (2016).,

43. Ulep M.G., Saraon S.K., McLea S.: J. Nurse Pract. 14, 129 (2018).

44. Massoud F., Léger G.C.: Can. J. Psychiatry 56, 579 (2011).

45. Marucci G., Buccioni M., Ben D.D., Lambertucci C., Volpini R., et al.: Neuropharmacology 190 (2021).

46. Alvarez X.A., Mouzo R., Pichel V., Pérez P., Laredo M., et al.: Methods Find Exp. Clin. Pharmacol. 21, 633 (1999).

47. Gareri P.: J. Alzheimers Dis. 56, 557 (2017).

48. Tham Y-C., Li X., Wong T.Y, Quigley H.A., Aung T., Cheng C-Y.: Ophthalmology 121, 2081 (2014).

49. Giraldi J.P., Virno M., Covelli G., Grechi G., De Gregorio F.: Int. Ophthalmol. 13, 109 (1989).

50. Parisi V., Centofanti M., Ziccardi L., Tanga L., Michelessi M., et al.: Graefes Arch. Clin. Exp. Ophthalmol. 253, 1327 (2015).

51. Rejdak R., Toczołowski J., Kurkowski J., Kamiński M.L., Rejdak K., et al.: Med. Sci. Monit. 9, PI24-8 (2003).

52. Gandolfi S., Marchini G., Caporossi A., Scuderi G., Tomasso L., et al.: Nutrients 12, 793 (2020).

53. Rejdak R., Toczołowski J., Solski J., Duma D., Grieb P.: Ophthalmic Res. 34, 146 (2002).

54. Schuettauf F., Rejdak R., Thaler S., Bolz S., Lehaci C. et al.: Exp. Eye Res. 83, 1128 (2006).

55. Davinelli S., Chiosi F., Di Marco R., Costagliola C., Scapagnini G.: Oxid. Med. Cell Longev. 2017, 26 pages (2017).

56. Yoon S.J., Lyoo I.K., Kim H.J., Kim T-S., Sung Y.H., et al.: Neuropsychopharmacology 35, 1165 (2010).

57. Brown E.S., Gabrielson B.: J. Affect. Disord. 143, 257 (2012).

58. Brown E.S., Gorman A.R., Hynan L.S.: J. Clin. Psychopharmacol. 27, 498 (2007). 
59. Renshaw P.F., Daniels S., Lundahl L.H., Rogers V., Lukas S.E.: Psychopharmacology 142, 132 (1999).

60. Bracken B.K., Penetar D.M., Rodolico J., Ryan E.T., Lukas S.E.: Pharmacol. Biochem. Behav. 98, 518 (2011).

61. Licata S.C., Penetar D.M., Ravichandran C., Rodolico J., Palmer C., et al.: J. Addict. Med. 5, 57 (2011).

62. Brown E.S., Van Enkevort E., Kulikova A., Escalante C., Nakamura A., et al.: Alcohol. Clin. Exp. Res. 43, 317 (2019).

63. Killgore W.D., Ross A.J., Kamiya T., Kawada Y., Renshaw P.F., Yurgelun-Todd D.A.: Int. J. Eat. Disord. 43, 6 (2010).
64. Roohi-Azizi M., Arabzadeh S., Amidfar M., Salimi S., Zarindast M.R., et al.: Clin. Neuropharmacol. 40, 1 (2017).

65. Ghajar A., Gholamian F., Tabatabei-Motlagh M., Afarideh M., Rezaei F., et al.: Hum. Psychopharmacol. 33 e2662 (2018).

66. Lozano Fernandez R.: Arzneimittelforschung 33, 1073 (1983).

67. Fioravanti M., Yanagi M.: Cochrane Database Syst. Rev. CD000269 (2004).

68. Cho H.J., Kim Y.J.: Methods Find. Exp. Clin. Pharmacol. 31, 171 (2009).

69. Dávalos A., Alvarez-Sabín J., Castillo J., DíezTejedor E., Ferro J., et al.: Lancet 380, 349 (2012). 